\title{
Detection of circulating tumor DNA in patients with advanced non-small cell lung cancer
}

\author{
Yu Yao ${ }^{1, *}$, Jinghao Liu ${ }^{2, *}$, Lei $\mathrm{Li}^{3, *}$, Yuan Yuan ${ }^{3, *}$, Kejun Nan ${ }^{1}$, Xin Wu ${ }^{3}$, Zhenyu \\ Zhang $^{3}$, Yi Wu ${ }^{2}$, Xin $\mathbf{L i}^{2}$, Jiaqi Zhu ${ }^{3}$, Xuehong Meng ${ }^{3}$, Longgang $\mathrm{Wei}^{3}$, Jun Chen ${ }^{2}$, \\ Zhi Jiang ${ }^{3}$ \\ ${ }^{1}$ Department of Medical Oncology, The First Affiliated Hospital of Xi'an Jiaotong University, Shanxi, China \\ ${ }^{2}$ Department of Lung Cancer Surgery, Tianjin Key Laboratory of Lung Cancer Metastasis and Tumor Microenvironment, \\ Tianjin Lung Cancer Institute, Tianjin Medical University General Hospital, Tianjin, China \\ ${ }^{3}$ Novogene Bioinformatics Institute, Beijing, China \\ *These authors contributed equally to this work
}

Correspondence to: Jun Chen, email: huntercj2004@yahoo.com Zhi Jiang, email: jiangzhi@novogene.com

Keywords: circulating tumor DNA, NSCLC, targeted sequencing, EGFR, gene fusion

Received: May 04, $2016 \quad$ Accepted: October 19, $2016 \quad$ Published: October 25, 2016

\section{ABSTRACT}

Circulating tumor DNA (ctDNA) isolated from plasma has great potential in identification of gene mutation in non-small cell lung cancers (NSCLC), which is a non-invasive technique and can avoid the inherent shortcomings of tissue biopsy. However the ability of NGS to detect gene mutation in plasma ctDNA has not been broadly explored. To assess the diagnostic ability of ctDNA for the total mutation profile, including single nucleotide variations (SNVs), insertions and deletions (indels) and gene rearrangements, we performed a targeted DNA sequencing approach to screen NSCLC related driver gene mutations in both tissue biopsies and matched blood plasma samples from 39 advanced NSCLC patients from China. The sensitivity of EGFR, KRAS, PIK3CA mutations and gene rearrangements detected in plasma ctDNA was $70.6 \%, 75 \%, 50 \%$ and $60 \%$, respectively and the overall concordance of gene mutations between tissue DNA and plasma ctDNA was $78.21 \%$. Our data provide evidence that ctDNA in plasma is likely to become an alternative source for cancerrelated mutations profiling in advanced NSCLC patients and targeted sequencing of ctDNA offers a promising perspective on precise diagnostics and may serve as a feasible option for clinical monitoring of NSCLC patients.

\section{INTRODUCTION}

Lung cancer is the leading cause of cancer-related mortality in China [1]. Non-small cell lung cancer (NSCLC), the most common subtype of lung cancer, is often characterized by unique driver gene mutation profiles [2-4]. Precise characterization of tumor mutation profiles is a fundamental part of personalized therapy. Tissue biopsies obtained in surgery are the "gold standard" for detecting oncogene mutations [5]. However, tissue biopsies have some inherent shortcomings in clinical practice. Mutations detected in different metastatic clones can be significantly diverse from each other or from the primary tumor tissue [6]. ctDNA is generated from apoptotic or necrotic tumor cells, circulating tumor cells or metastatic tumors. DNA fragments carrying tumorspecific genetic alterations can be extracted from blood plasma for further examination [7-9]. This non-invasive type of "liquid biopsy" can be taken easily and repeatedly over the course of a patient's treatment, and meanwhile, ctDNA may potentially reflect all heterogeneous genetic mutation profiles, with overcoming other common obstacles in conventional tissue biopsy. Given that, ctDNA provides new insight into diagnosis, prognosis and patient follow-up compared to traditional tissue biopsy.

Somatic mutation analysis of known oncogenes, such as epidermal growth factor receptor $(E G F R)$, has become a routine clinical test in NSCLC for patient prognosis and targeted drug selection [10]. Approximately $10 \%$ of patients with NSCLC in the US 
and $35 \%$ in East Asia have somatic EGFR mutations [11]. EGFR mutation status is an useful predictor of efficacy for $E G F R$ tyrosine kinase inhibitors (EGFRTKIs) [12]. Over the past decade, there is increasing evidence that $A L K$ rearrangements are more commonly found in NSCLC patients who are light smokers or never smokers. And $A L K$ rearrangements are also associated with younger age and adenocarcinomas. Most recently, EML4- $A L K$ fusions are recognized to be potential driver mutations in NSCLC. NSCLC patients harboring $A L K$ fusions derive more benefits from ALK-TKIs. Therefore, from a clinical perspective, it is essential to accurately and comprehensively assess tumor-related gene mutation profiles, including SNVs, indels and gene rearrangements in NSCLC patients.

In recent years, several studies have confirmed that NSCLC-related driver gene mutations (such as EGFR and KRAS) could be detected in plasma DNA by a variety of methods, including BEAMing (beads, emulsion, amplification, and magnetics) technology [13], peptide nucleic acid (PNA)-mediated polymerase chain reaction (PCR) [14] and the Scorpion ARMSbased EGFR mutation detection method [15]. And it is reported that EGFR exon 19 deletion and L858R mutation would be detected from circulating cell-free DNA from NSCLC patients [16]. Concordant NSCLC driver gene profiles between ctDNA and primary tumor DNA has been reported by several groups. Using mutant enriched liquid chip (MEL), Zhang has detected EGFR, KRAS, BRAF and PIK3CA in 86 tissue samples and matched plasma samples in NSCLC patients, with overall agreements of $64 \%, 97 \%$, $98 \%$ and $97 \%$, respectively [17]. NSCLC driver gene mutations in matched tumor DNA and ctDNA have also been identified by the semiconductor-based targeted sequencing method, with an overall concordance of 76\% [18]. Using Ion Torrent's Ampliseq hotspot cancer panel, Ronald Lebofsky and his colleagues demonstrate that 28 of 29 mutations detected in metastasis biopsies have also been found in matched ctDNA among 27 samples [19]. However, previous studies are focused on SNVs and indels of the driver genes, whether the gene rearrangement detected from plasma ctDNA is accordance with that in tissue DNA has not been illustrated yet. Fusions of oncogenes, such as ALK, ROS1 and RET, are involved tumorigenesis and are recognized as likely future predictive lung tumor biomarkers [20]. Detection of gene rearrangements from plasma ctDNA would have a substantial impact on the clinical diagnostic and prognostic stratification of NSCLC.

In this study, we used a targeted sequencing approach based on the Illumina platform to detect and compare NSCLC driver gene alterations, including point mutations, indels and gene rearrangements, simultaneously in tissue biopsies and matched plasma samples from 39 Chinese patients with advanced NSCLC.

\section{RESULTS}

\section{Patient characteristics}

Tissue and matched peripheral blood samples obtained from 39 NSCLC patients were analyzed. Patient clinical characteristics are listed in Table 1. Participants in this study cohort, including 20 females and 19 males, were diagnosed with stage IIIa to IV NSCLC. A total of 34 of 39 patients $(87 \%)$ had adenocarcinoma and 5 of 39 patients $(13 \%)$ had squamous cell carcinoma. The majority of patients $(29 / 39,74.4 \%)$ were non-smokers. Most of patients (36 of $39,92.3 \%$ ) were treatment naïve. In the three treatment-experienced patients, two had first line target therapy during the past 1.5 years and the other one received chemotherapy.

\section{Sequencing coverage analysis}

All samples, consisting of plasma, white blood cell (WBC) and tissue, were sequenced using paired-end strategy on an Illumina HiSeq platform. More than $90 \%$ of the bases had a phred quality score greater than 20 (error rate less than $1 \%$ ). We achieved an average sequencing depth on target in all tested samples: median depth of $855.17 \times$ (range $215.57 \times-3370.70 \times)$ for tissue DNA samples, median depth of $2022.29 \times$ (range $925.00 \times-4786.10 \times$ ) for plasma ctDNA samples, and median depth of $1114.52 \times$ (range $531.29 \times-2801.77 \times$ ) for WBC samples (Figure 1).

\section{Comparison of matched tissue and plasma mutations}

SNVs, Indels and fusions of NSCLC-related genes, including EGFR, KRAS, PIK3CA, ALK and RET, detected in 39 advanced NSCLC patients were listed in Tables 2 and 3. The concordant mutations detected both in tissue DNA and plasma ctDNA in 18.5 of 39 patients (47.43\%), and no somatic mutations were found from both samples in 12 patients (30.77\%), and mutations were only found from tissue DNA in 8.5 patients (21.80\%) (Figure 2A). Gene mutations detected in both tissue DNA and plasma ctDNA were EGFR, KRAS, ELM4-ALK rearrangements and $P I K 3 C A$, and the overlap mutation rates in tissue and plasma of them were $30.77 \%, 7.70 \%, 6.40 \%$ and $2.56 \%$, respectively (Figure 2B).

The sensitivity of detecting mutations in plasma ctDNA was $68.5 \%(18.5 / 27,95 \% \mathrm{CI}$ is $47.8-84.1 \%)$ and the positive predictive value (PPV) was $100 \%$ $(18.5 / 18.5,95 \% \mathrm{CI}$ is $78.6-100 \%)$; the specificity was $100 \%(12 / 12,95 \% \mathrm{CI}$ is $69.9-100 \%)$ and the negative predictive value (NPV) was $58.5 \%(12 / 20.5,95 \% \mathrm{CI}$ is $35.4-78.7 \%$ ) and the overall concordance between tissue and plasma was $78.21 \%(30.5 / 39)$. The mutation frequencies of SNVs and indels from tissue DNA (average of $24.10 \%$, with a range of $0.30 \%-52.00 \%$ ) 


\section{Characteristics}

Age (years)

Mean (SD)

Median (range)

Sex

Male

Female

Pathological diagnosis

Non-small cell lung cancer

Adenocarcinoma

Squamous cell carcinoma

Tumor stage

IIIA

IIIB

IV

Smoking history

Smoker

Non-smoker

Treatment history

Treatment naïve patients

Treatment experienced patients

Chemotherapy history

Undertook chemotherapy

Not undertook chemotherapy

Targeted therapy history

Treatment with target therapy

Not treatment with target therapy

\section{Number}

$59(11.60)$

$62(28-78)$

$19(48.7 \%)$

$20(51.3 \%)$

$39(100.0 \%)$

$34(87.2 \%)$

$5(12.8 \%)$

$5(12.8 \%)$

$3(7.7 \%)$

$31(79.5 \%)$

$10(25.6 \%)$

$29(74.4 \%)$

$35(89.7 \%)$

$4(10.3 \%)$

$1(2.6 \%)$

$38(97.4 \%)$

$1(2.6 \%)$

$38(97.4 \%))$

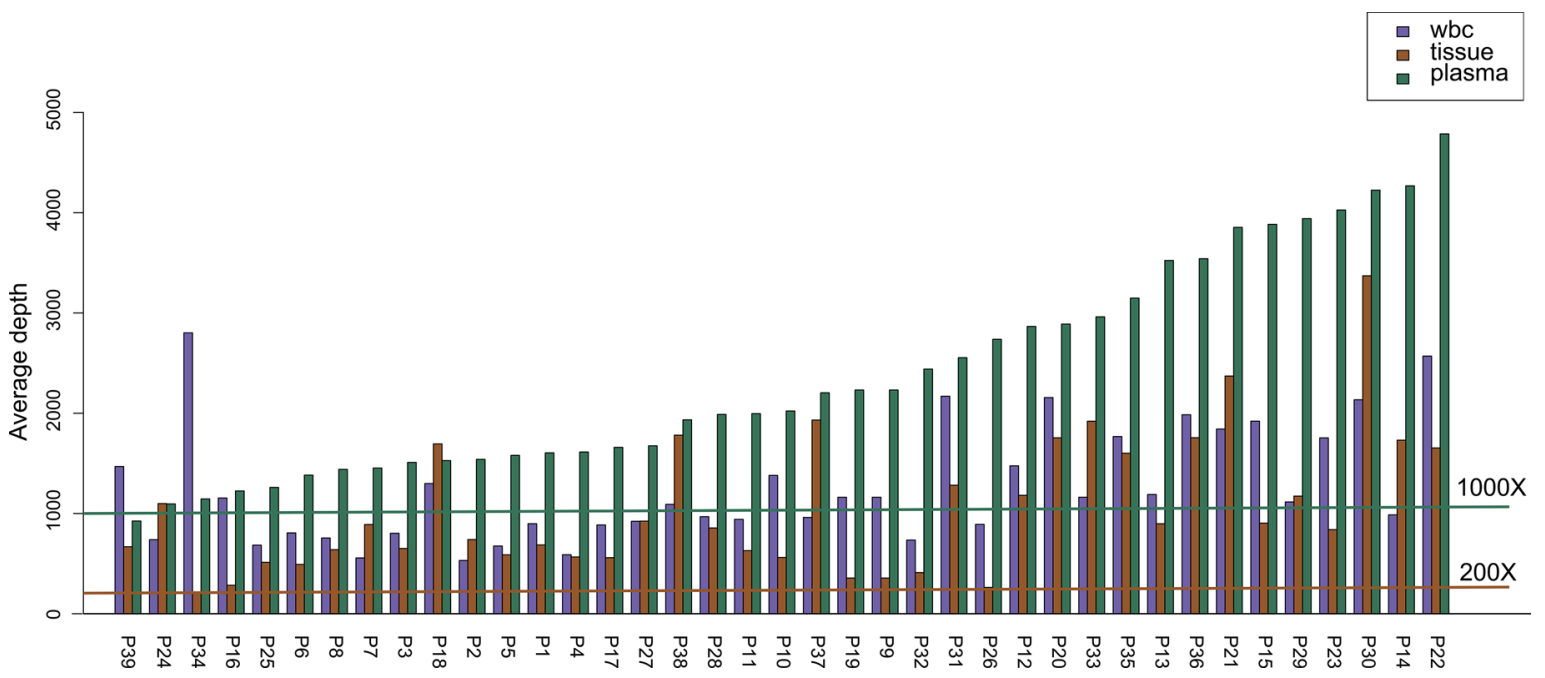

Figure 1: Average depth of the NGS assay. Average sequencing depth of target in 39 matched tissue, plasma and white blood cell (WBC) samples. For the tissue and WBC samples, average sequencing depth of target is more than $200 \times$ (brown line). For plasma samples, average sequencing depth of target is more than $1000 \times$ (dark green line). 
Table 2: Single nucleotide variations and indels detected in tissue DNA and plasma ctDNA

\begin{tabular}{|c|c|c|c|c|c|c|c|c|c|c|}
\hline \multirow{2}{*}{ Patients } & \multirow{2}{*}{ Cancer type } & \multirow{2}{*}{ Tumor stage } & \multirow{2}{*}{ Position } & \multirow{2}{*}{ Gene } & \multirow{2}{*}{ Mutation } & \multirow{2}{*}{ Mutation type } & \multicolumn{3}{|c|}{$\%$ variants } & \multirow{2}{*}{ Concordance (Yes or No) } \\
\hline & & & & & & & Tissue DNA & Plasma DNA & WBC DNA & \\
\hline \multirow{2}{*}{ P4 } & \multirow{2}{*}{$\mathrm{AC}$} & \multirow{2}{*}{ IIIB } & chr7:55249071 & $E G F R$ & p.T790M & SNV & 0.30 & 7.70 & 0 & Yes \\
\hline & & & $\operatorname{chr} 7: 55259515$ & $E G F R$ & p.L858R & SNV & 23.30 & 11.60 & 0 & Yes \\
\hline P6 & $\mathrm{AC}$ & IV & chr7:55259515 & $E G F R$ & p.L858R & SNV & 12.30 & 5.10 & 0 & Yes \\
\hline P8 & $\mathrm{AC}$ & IV & chr7:55242465 & $E G F R$ & p.745_750del & DEL & 20.00 & 0.20 & 0 & Yes \\
\hline P9 & $\mathrm{AC}$ & IV & chr7:55259515 & $E G F R$ & p.L858R & SNV & 28.50 & 5.00 & 0 & Yes \\
\hline P10 & $\mathrm{AC}$ & IV & $\operatorname{chr} 7: 55259515$ & $E G F R$ & p.L858R & SNV & 6.00 & 7.00 & 0 & Yes \\
\hline P11 & $\mathrm{AC}$ & IV & $\operatorname{chr} 7: 55259515$ & $E G F R$ & p.L858R & SNV & 25.00 & 0.70 & 0 & Yes \\
\hline P19 & $\mathrm{AC}$ & IIIA & chr3:178936091 & PIK3CA & p.E545K & SNV & 18.70 & 4.90 & 0 & Yes \\
\hline P27 & $\mathrm{AC}$ & IV & chr7:55241707 & $E G F R$ & p.G719S & SNV & 51.00 & 0.20 & 0 & Yes \\
\hline P29 & $\mathrm{AC}$ & IV & chr7:55242466 & $E G F R$ & p.746_750del & DEL & 52.00 & 7.20 & 0 & Yes \\
\hline P31 & $\mathrm{AC}$ & IV & chr7:55259515 & $E G F R$ & p.L858R & SNV & 38.00 & 9.70 & 0 & Yes \\
\hline P32 & $\mathrm{AC}$ & IV & chr7:55242466 & $E G F R$ & p.746_748del & DEL & 34.00 & 9.00 & 0 & Yes \\
\hline P34 & $\mathrm{AC}$ & IV & chr12:25398284 & $K R A S$ & p.G12V & SNV & 28.90 & 9.80 & 0 & Yes \\
\hline P35 & $\mathrm{AC}$ & IV & chr12:25398285 & $K R A S$ & p.G12C & SNV & 19.70 & 5.00 & 0 & Yes \\
\hline P36 & $\mathrm{AC}$ & IV & chr7:55242467 & $E G F R$ & p.746_751del & DEL & 30.30 & 8.10 & 0 & Yes \\
\hline P37 & $\mathrm{AC}$ & IV & chr7:55259515 & $E G F R$ & p.L858R & SNV & 12.70 & 0.20 & 0 & Yes \\
\hline P39 & $\mathrm{AC}$ & IIIB & chr12:25398284 & $K R A S$ & p.G12V & SNV & 26.00 & 0.69 & 0 & Yes \\
\hline \multirow{2}{*}{ P1 } & \multirow{2}{*}{$\mathrm{AC}$} & \multirow{2}{*}{ IV } & chr3:178936091 & $P I K 3 C A$ & p.E545K & SNV & 23.30 & 0 & 0 & No \\
\hline & & & chr7:55259515 & $E G F R$ & p.L858R & SNV & 45.00 & 0 & 0 & No \\
\hline $\mathrm{P} 2$ & $\mathrm{AC}$ & IV & chr7:55242466 & $E G F R$ & p.746_748del & DEL & 39.40 & 0 & 0 & No \\
\hline P5 & $\mathrm{AC}$ & IV & $\operatorname{chr} 12: 25398284$ & $K R A S$ & p.G12A & SNV & 15.20 & 0 & 0 & No \\
\hline P17 & $\mathrm{AC}$ & IV & chr7:55259524 & $E G F R$ & p.L861Q & SNV & 16.30 & 0 & 0 & No \\
\hline P23 & $\mathrm{AC}$ & IIIA & chr7:55242466 & $E G F R$ & p.746_750del & DEL & 10.50 & 0 & 0 & No \\
\hline $\mathrm{P} 25$ & $\mathrm{AC}$ & IV & chr7:55242466 & $E G F R$ & p.L858R & SNV & 15.50 & 0 & 0 & No \\
\hline P26 & $\mathrm{AC}$ & IV & chr2:29445213 & $A L K$ & p.L1171T & SNV & 10.70 & 0 & 0 & No \\
\hline
\end{tabular}

AC: adenocarcinoma; SNVs: single nucleotide variations; DEL: deletion, WBC: white blood cell.

Table 3: Gene fusions detected in tissue DNA and plasma ctDNA

\begin{tabular}{|c|c|c|c|c|c|c|c|c|c|}
\hline \multirow{2}{*}{ Patients } & \multirow{2}{*}{ Cancer type } & \multirow{2}{*}{ Tumor stage } & \multirow{2}{*}{$5^{\prime}$ gene-exon } & \multirow{2}{*}{$3^{\prime}$ gene-exon } & \multirow{2}{*}{ Fusions } & \multicolumn{2}{|c|}{ Detected fusion reads } & \multirow{2}{*}{$\begin{array}{l}\text { Concordance } \\
\text { (Yes or No) }\end{array}$} & \multirow{2}{*}{ Confirmation } \\
\hline & & & & & & Tissue DNA & Plasma & & \\
\hline $\mathrm{P} 24$ & $\mathrm{AC}$ & IV & KIF5B-exon 15 & RET-exon 12 & KIF5B-RET & 77 & 0 & No & Sanger \\
\hline $\mathrm{P} 26$ & $\mathrm{AC}$ & IV & EML4-exon 2 & $A L K$-exon 19 & EML4-ALK & 11 & 13 & Yes & FISH \\
\hline P28 & $\mathrm{AC}$ & IV & EML4-exon 7 & $A L K$-exon 19 & EML4-ALK & 4 & 15 & Yes & Sanger \\
\hline P30 & $\mathrm{AC}$ & IV & EML4-exon 7 & $A L K$-exon 19 & EML4-ALK & 214 & 379 & Yes & $\mathrm{IHC}$ \\
\hline P33 & $\mathrm{AC}$ & IV & EML4-exon 13 & ALK-exon 19 & EML4-ALK & 93 & 0 & No & NA \\
\hline
\end{tabular}

AC: adenocarcinoma; NA: not available for validation.

were higher than that from matched plasma ctDNA (average of $3.70 \%$, with a range of $0.20 \%-11.60 \%$ ).

\section{NSCLC-related driver gene mutations in matched tissue DNA and plasma ctDNA}

Our research priority was to determine the concordance between tissue DNA and plasma ctDNA in NSCLC-related mutation profile, which has high prognostic and therapeutic significance. In the 39 advanced NSCLC patients, we identified gene mutations, including EGFR, KRAS, PIK3CA, ALK and RET (Figure 3) and the sensitivity, specificity, PPV and NPV of detecting those mutations in ctDNA were illustrated in Table 4. For gene rearrangements, 5 were detected from tissue DNA, and 3 were successfully identified in matched plasma ctDNA (Figure 3). EML4-ALK gene fusions were detected in both the tissue and matched plasma of three patients (P-26, P-28 and P-30) and confirmed by routine clinical approaches (FISH, Sanger sequencing or IHC; Table 3). One discordant mutation, KIF5B-RET gene fusion in P-24, was only found in tissue DNA, as validated 
by Sanger sequencing (Table 3). Another inconsistent mutation, EML4-ALK gene fusion, was only observed in a tissue sample from patient P-33. We were not able to further verify this gene fusion by Sanger sequencing because the DNA has been run out. But we observed a strong signal (93 reads) in the bam file of the tissue samples (Table 3). Concordant results between NGS and routine clinical approaches (FISH, IHC or Sanger sequencing) demonstrated that target sequencing approach using ctDNA has significant potential in detecting driver gene rearrangements in NSCLC patients.

In summary, 30 mutations in 39 patients were identified in tissue samples, and the overall mutation percentages of EGFR, KRAS, PIK $3 C A, A L K$ rearrangements detected from plasma ctDNA were similar with that from tissue DNA (Figure 4A). We detected 17 SNVs, 6 indels, and 5 gene fusions in tissue DNA samples and $12 \mathrm{SNVs}, 4$ indels and 3 fusions in plasma ctDNA (Figure 4B). There was no significant difference of mutational frequencies for each genes and variant type between plasma ctDNA and tissue DNA.

\section{Ultra-low frequency mutations analysis}

Minimum mutation frequencies detected in matched tissue and plasma samples were $0.30 \%$ and $0.20 \%$, respectively (Table 5). All SNVs and indels detected in matched tissue DNA and plasma ctDNA were carefully evaluated using the Integrative Genomics Viewer (IGV). We did not find any reads supporting those variants in the bam files of the matched plasma ctDNA. In addition, digital PCR was used to validate mutations with ultra-low allele frequencies $(<0.50 \%)$ and discordant mutations (Table 5). Mutation frequencies detected by NGS were similar to those detected by digital PCR $\left(R^{2}=0.97\right)$. In the plasma ctDNA of patients P-1, P-23 and P-25, the mutation frequencies detected by digital PCR were zero or extremely low (less than $0.16 \%$ ). In the tissue or plasma samples of patients P-4, P-8, P-11 and P-37, the mutations detected by NGS (mutated allele frequency $>0.20 \%$ ) were successfully detected by digital PCR. These data suggested that our NGS data is agreement with that of digital PCR.

\section{DISCUSSION}

In matched tissue and plasma samples obtained from 39 advanced NSCLC Chinese patients, we applied targeted sequencing to detect various NSCLC-related driver gene mutations. In addition to the SNVs and indels, gene rearrangements were also analyzed from both tissue DNA and plasma ctDNA. The overall concordance between tissue and plasma DNA was $78.21 \%$ and overall sensitivity and specificity of detecting mutations in ctDNA were $68.5 \%(95 \% C I=47.8-84.1 \%)$ and $100 \%(95 \%$ $C I=69.9 \%-100.0 \%$ ), respectively. These results indicated that NGS data regarding driver gene mutations in ctDNA could be useful for molecular diagnostics in advanced NSCLC patients.

In our study, some mutations were only found in tissue DNA but not in plasma ctDNA. This may be due to genomic DNA from necrotic white blood cells is released into the blood and diluted ctDNA in the plasma [21]. The amount of ctDNA in cancer patients likely associated with tumor burden, status of metastasis, vascularity, cellular turnover, and response of therapy [22, 23]. In addition, it is also influenced by clearance, degradation and other physiological filtering events involving blood and lymphatic circulation [21]. However, four ultra-low frequency mutations (minimum mutation frequency of $0.20 \%$ ) were detected by NGS, which were verified by digital PCR (Table 4), indicating that using plasma ctDNA to detect low frequency somatic mutations in NSCLC patients is applicable. Although the mutation frequency and gene mutation number in plasma ctDNA were less

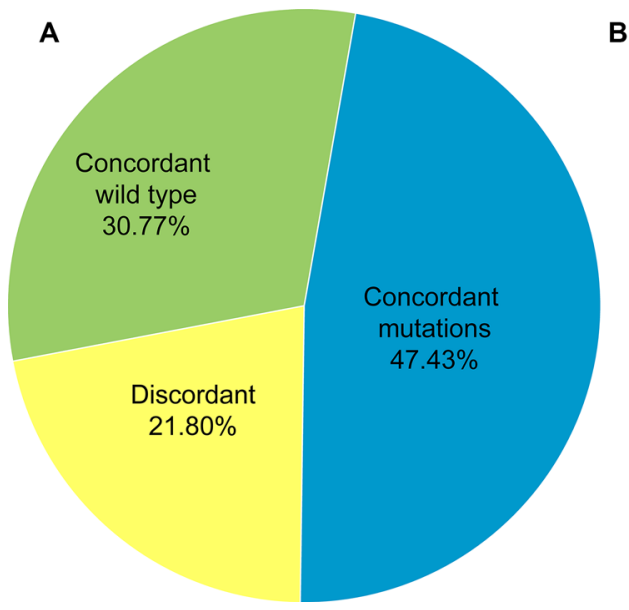

B
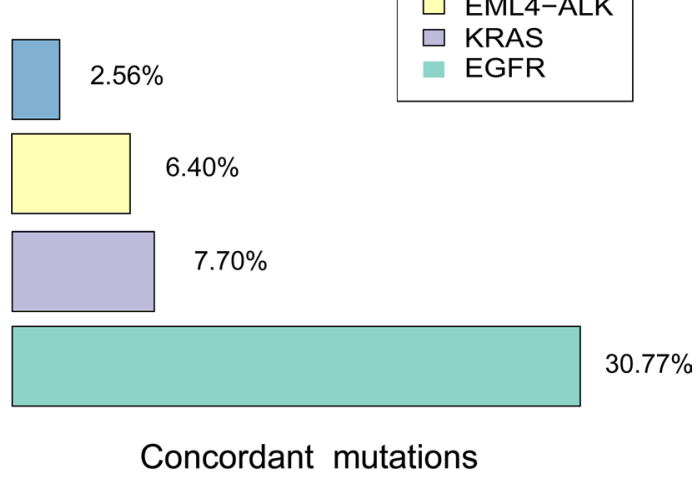

Figure 2: Comparison of matched tissue and plasma mutations. (A) Percentage of concordant (wild type and mutations) and discordant mutations in matched tissue and plasma samples. (B) Percentage of NSCLC-related driver gene mutations detected in both matched tissue and plasma samples. 
Table 4: The performance of mutation detected in plasma ctDNA

\begin{tabular}{cccccc}
\hline Genes & Sensitivity (\%) & Positive predictive value (\%) & Specificity (\%) & Negative predictive value (\%) & Concordance (\%) \\
\hline$E G F R$ & $70.6(12 / 17)$ & $100(12 / 12)$ & $100(22 / 22)$ & $81.5(22 / 27)$ & $84.18(34 / 39)$ \\
KRAS & $75(3 / 4)$ & $100(3 / 3)$ & $100(35 / 35)$ & $97.22(35 / 36)$, & $97.44(38 / 39)$ \\
PIK3CA & $50(1 / 2)$ & $100(1 / 1)$ & $100(37 / 37)$ & $97.37(37 / 38)$ & $97.44(38 / 39)$ \\
Gene fusions & $60(3 / 5)$ & $100(3 / 3)$ & $100(34 / 34)$ & $94.44(34 / 35)$ & $94.87(37 / 39)$ \\
In total & $68.5^{*}(18.5 / 27)$ & $100(19 / 19)$ & $100(12 / 12)$ & $58.54(12 / 20.5)$ & $78.21(30.5 / 39)$ \\
\hline
\end{tabular}

*: P26 harbored an ALK p.L171T which was only found in tissue DNA and an EMLK-ALK mutation which was found in both tissue DNA and plasma ctDNA. To maintain a total sample number of $39, \mathrm{P} 26$ was counted as 0.5 in each category.

than that in tissue DNA, plasma ctDNA displayed similar driver gene mutation profile with tissue DNA. Therefore it is clinically beneficial to detect gene mutation in plasma ctDNA in advanced NSCLC patients.

Many studies have shown the sensitivity of detecting gene mutation in plasma ctDNA is largely dependent on detection techniques. The sensitivity of EGFR mutation detected in ctDNA is $80.3 \%(49 / 61)$ by BEAMing [24], 66.7\% (34/51) by PNA-PCR [25], 72.1\% (44/61) by ARMS [26]. In our study, using a NGS method of targeted sequencing based on Illumina HiSeq platform the sensitivity of EGFR mutation detected in plasma ctDNA was $70.6 \%$. Apparently, the sensitivity of EGFR mutations detection in ctDNA by NGS was not quite different from other methods. However, the greatest advantage of NGS is that it can detect large-scale gene mutations simultaneously whereas others cannot. In addition to the EGFR mutations, the sensitivity of detecting $K R A S$, $P I K 3 C A$ and gene fusions (EML4-ALK and KIF5B-RET) in plasma ctDNA was $75 \%, 50 \%$ and $60 \%$, respectively. Sacher et al. using digital PCR to detect EGFR and KRAS mutations in plasma samples with sensitivity of $78.4 \%$ and $64 \%$, respectively [27]. For several discordant mutations and the mutations with ultra-low frequencies $(<0.50 \%)$ by NGS, we also performed digital PCR to validate the data. Our data revealed that our NGS results were highly consistent with digital PCR results.

EGFR mutations predict better outcomes in NSCLC patients with EGFR tyrosine kinase inhibitors therapy $[28,29]$. In present work, we showed the EGFR mutations rate of $43.6 \%$ (17 of 39 ) in tissue DNA and $30.77 \%$ (12 of 39 ) in plasma ctDNA. Previous studies

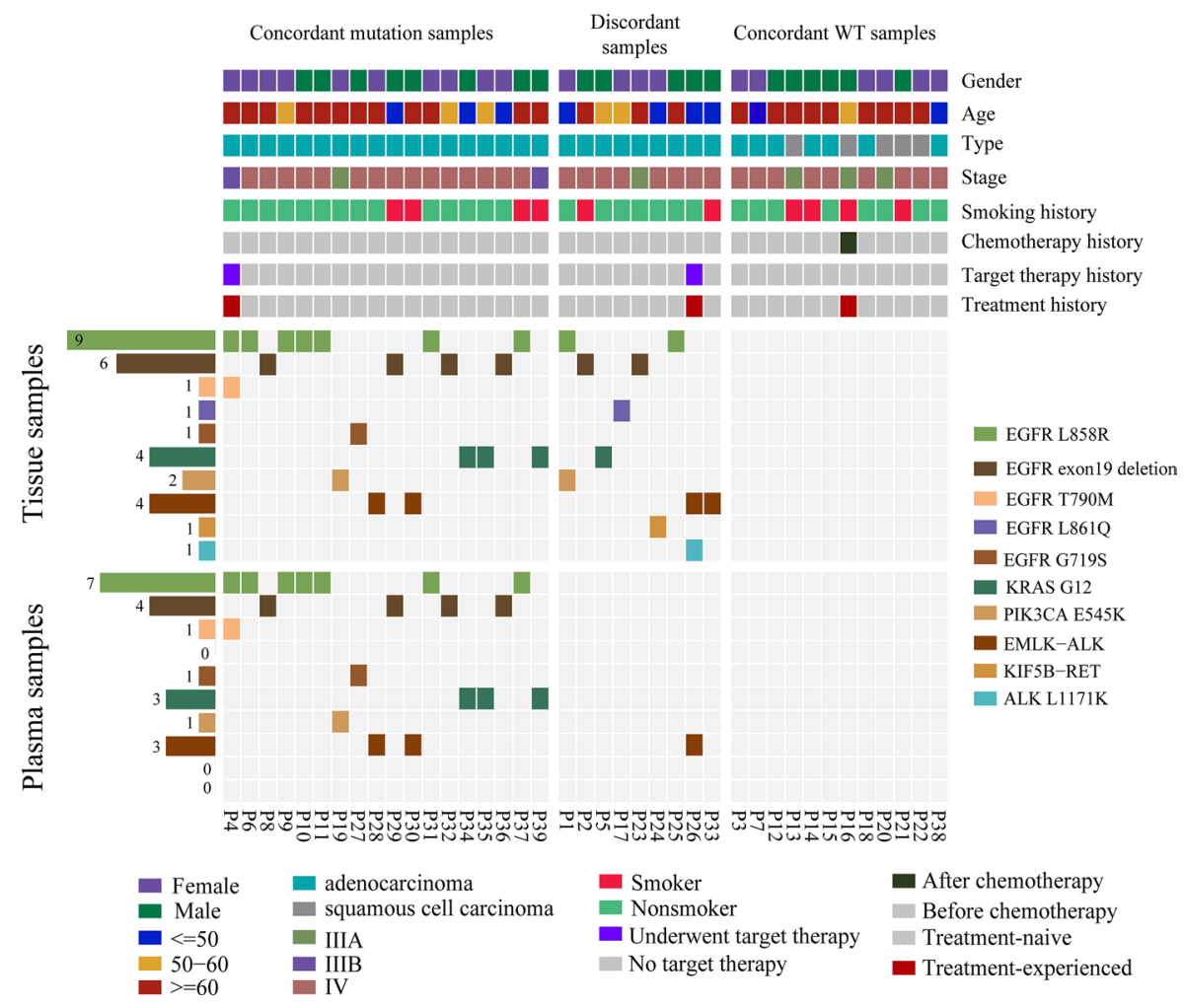

Figure 3: Mutation patterns of tissue and plasma samples from 39 patients with non-small cell lung cancer. Clinical characteristics of all 39 NSCLC patients according to the legend. Mutation patterns of tissue and plasma samples from 39 patients are shown in the heat map. Gene mutation frequencies in tissue and plasma samples are shown on the left. All the SNVs and indels detected in discordant samples were only from tissue samples. 
Table 5: Ultra-low frequency mutations verified by digital PCR

\begin{tabular}{|c|c|c|c|c|c|c|c|c|c|c|}
\hline \multirow{2}{*}{ Patients } & \multirow{2}{*}{ Cancer type } & \multirow{2}{*}{ Cancer stage } & \multirow{2}{*}{ Position } & \multirow{2}{*}{ Gene } & \multirow{2}{*}{ Mutation } & \multirow{2}{*}{ Mutation type } & \multicolumn{2}{|c|}{$\%$ variants by NGS } & \multicolumn{2}{|c|}{$\%$ variants by digital $P C R$} \\
\hline & & & & & & & Tissue & Plasma & Tissue & Plasma \\
\hline \multirow{2}{*}{ P1 } & \multirow{2}{*}{$\mathrm{AC}$} & \multirow{2}{*}{ IV } & chr3:178936091 & PIK3CA & p.E545K & SNV & 23.30 & 0 & 25.50 & 0.10 \\
\hline & & & chr7:55259515 & $E G F R$ & p.L858R & SNV & 45.00 & 0 & 40.20 & 0 \\
\hline P4 & $\mathrm{AC}$ & IIIB & chr7:55249071 & $E G F R$ & p.T790M & SNV & 0.30 & 7.70 & 0.46 & 6.90 \\
\hline P8 & $\mathrm{AC}$ & IV & chr7:55242465 & $E G F R$ & p.745_750del & DEL & 20.00 & 0.20 & NA & 0.47 \\
\hline P11 & $\mathrm{AC}$ & IV & chr7:55259515 & $E G F R$ & p.L858R & SNV & 25.00 & 0.70 & 25.04 & 0.93 \\
\hline P23 & $\mathrm{AC}$ & IIIA & chr7:55242466 & $E G F R$ & p.746_750del & DEL & 10.05 & 0 & 17.55 & 0 \\
\hline P25 & $\mathrm{AC}$ & IV & chr7:55242466 & $E G F R$ & p.L858R & SNV & 15.50 & 0 & 13.65 & 0.16 \\
\hline P37 & $\mathrm{AC}$ & IV & $\operatorname{chr} 7: 55259515$ & $E G F R$ & p.L858R & SNV & 12.70 & 0.20 & NA & 0.25 \\
\hline
\end{tabular}

AC: adenocarcinoma; SNVs: single nucleotide variations; DEL: deletion, NA: not available by digital PCR.

have showed that $E G F R$ mutation frequency in tumor is $28.4 \%(147 / 517)$ [30] and plasma samples is $34.3 \%$ (79 of 230) [31] in Chinese populations, respectively. As far as we known, sex, smoking status and histology types correlated significantly with EGFR mutation frequency [15] and EGFR mutation are more commonly detected in non-smokers [30]. However, due to the small cohort of patients used in this work, we did not observed a significant difference or correlation between the driver gene mutations or EGFR mutations and smoking history or disease stages (data not shown). The small discrepancies in EGFR frequency between our results and previous studies may mainly arise from the small cohort of patients. Additionally, the incidence of KRAS, PIK3CA and EML4$A L K$ mutations in the present work were $10.3 \%, 5.1 \%$, $12.8 \%$ in tissue DNA and $7.7 \%, 2.6 \%$ and $7.7 \%$ in plasma ctDNA which were consistent with previous reports [32].

Since acquired resistance is very common in NSCLC patients after treated with target therapy for a period, assessment the driver gene mutations profile is essential for diagnostics and target therapy for NSCLC patients. Patients with EGFR L858R were sensitive to EGFR-TKIs, such as gefitinib [33] and erlotinib [34], but almost half of the patients developed resistance to EGFR-TKIs by acquiring the secondary mutation T790M $[35,36]$. Patient P-4 was first identified EGFR exon 21 mutation by liquid biochips. After first line treatment with gefitinib for one and a half years, the patient appeared to acquire EGFR-TKI resistance. At this point, EGFR L858R and T790M mutations were found in both tissue and plasma samples by NGS, which could well explain the EGFR-TKI resistance developed in patient P-4. Approximately 3-7\% of lung cancer patients harbor $A L K$ fusions [37]. Crizotinib treatment was administered to patient P-26 when he was diagnosed with EML4-ALK fusion by FISH one and a half years ago. A secondary mutation, ALK L1171T was found in tissue DNA by NGS, which is interpretable for crizotinib resistance in patient P-26 [38]. Clinically, in the vast majority of cases, $A L K$ rearrangements are non-overlapping with $E G F R$ mutations [39, 40]. However, some evidence showed that the presence of EML4-ALK gene rearrangement is
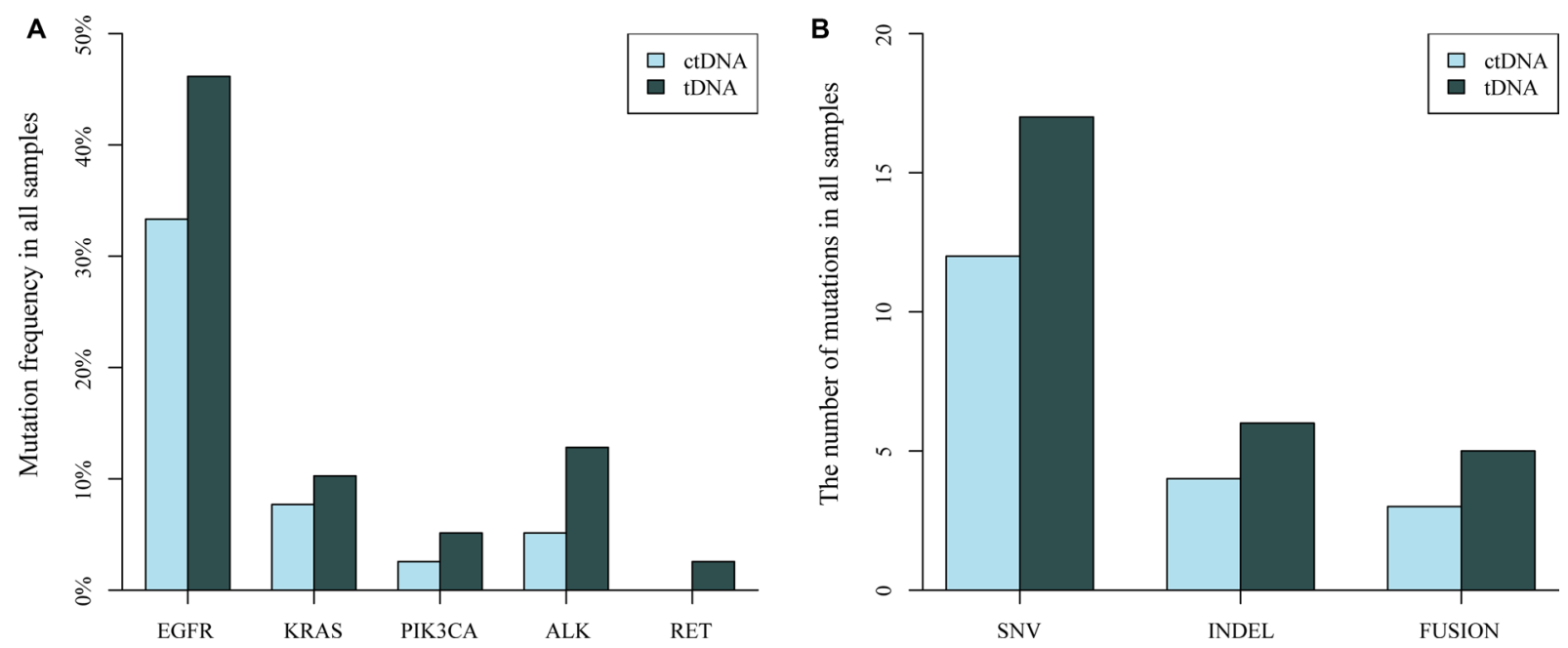

Figure 4: Comparison of the distribution of driver gene mutations identified in NSCLC tissue DNA (tDNA) and plasma DNA (ctDNA) samples. (A) Mutation frequency of $E G F R, K R A S, P I K 3 C A, A L K$ and $R E T$ in 39 sample pairs. (B) The number of mutation types (SNV, INDEL and gene fusion) detected in 39 paired samples. 
associated with EGFR-TKIs resistance among patients with metastatic diseases [41, 42]. In our present work, we did not found ALK rearrangements overlapping with $E G F R, P I K C 3 A$ or $K R A S$ in any patients with advanced NSCLC.

The sensitivity of gene fusions detected in matched tissue and plasma samples were less than SNVs, which may be due to the small cohort of patients. There are only 5 gene fusions but 17 SNVs detected in 39 NSCLC patients, which may influence the sensitivity calculation. In fact, the overall concordance of gene fusions in $94.87 \%$ (37/39) is higher than SNVs $(87.2 \%, 34 / 39)$. It is worthy to notice that the different principle of variant calling approaches. For SNVs, we used minimum number of reads carrying the mutation to find the real mutations, but for gene fusions we used the minimum number of softclip reads to obtain the true fusions. The filters for gene fusions are more stringent than SNVs and that's why the low frequency of gene fusions was not found in plasma samples.

In conclusion, the sequencing approach described herein can be used to detect gene mutations, such as SNVs, indels and gene fusion, in both plasma and tumor tissue from patients with advanced NSCLC. Our results showed a high concordance of gene mutations found in plasma samples and paired tissue samples. We therefore believe that ctDNA in plasma is likely to become an alternative source for cancer-related mutations profiling in advanced NSCLC patients, and is useful for molecular diagnostics, prognosis and targeted drug selection.

\section{MATERIALS AND METHODS}

\section{Ethics statement}

This study was approved by the Ethics Committees of The First Affiliated Hospital of Xi'an Jiao Tong University and Tianjin Medical University General Hospital. Thirty-nine patients with advanced NSCLC were recruited and patients signed informed consent for use of their blood plasma and tissue biopsy. All clinical data and samples were received anonymously.

\section{Sample collection and DNA extraction}

Peripheral blood was collected before surgery in one week for all the patients. Tissue samples were collected from the metastatic nodules for 11 patients, who were found pleura metastasis in the surgery. For the others without pleura metastasis, tissue samples were collected from primary site. Three sample types were examined for mutation profiles: fresh or formalin-fixed paraffin embedded (FFPE) tumor tissue, peripheral blood lymphocytes and plasma. The QIAAmp nucleic acid kit (Qiagen NV, Venlo, The Netherlands) and QIAAmp DNA FFPE tissue kit (Qiagen) were used in DNA extraction from fresh frozen biopsy and FFPE samples, respectively. Peripheral blood samples were collected in cfDNA BCT tubes (Streck Laboratories, Omaha, NE), stored at $15-30^{\circ} \mathrm{C}$ and processed within 72 hours. Each tube was centrifuged at $1600 \mathrm{~g}$ for 10 minutes at room temperature. Pellets containing peripheral blood lymphocytes were stored at $-20^{\circ} \mathrm{C}$ for further use. Aliquots of plasma were centrifuged at a maximum speed at $16000 \mathrm{~g}$ for another 10 minutes. The supernatant was transferred to sterile $1.5 \mathrm{ml}$ tubes and stored at $-80^{\circ} \mathrm{C}$ before extraction. Circulating tumor DNA was extracted from $5 \mathrm{ml}$ plasma with the QIAamp circulating nucleic acid kit (Qiagen) following the manufacturer's instructions using a QIAvac 24 plus vacuum manifold (Qiagen). To enhance ctDNA yields, carrier RNA was added to lysis buffer. Germline genomic DNA from peripheral blood lymphocytes was extracted using the RelaxGene Blood DNA System (TianGen Biotech Co., Ltd., Beijing, China). DNA from both tissue biopsy and plasma samples were quantified by Qubit 2.0 (Life Technologies) according the recommended protocol.

\section{Library construction, hybridization and sequencing}

The library was constructed using a KAPA Hyper Prep kit (Kapa Biosystems) according to the manufacturer's instructions. The prepped libraries were hybridized with two different hybridization reagents and blocking agents in SureSelectXT and SureSelectQXT Target Enrichment System (Agilent Technologies). Because we used adaptors which were different from those included in the kits, additional blocking oligos and a P5/P7 primer were applied instead of the primers provided. The size of the prepped library was qualified using a 2100 Bioanalyzer (Agilent Technologies), and quality was assessed using the StepOnePlus real-time PCR system (Life Technologies). The concentration of each library was quantified using a QPCR NGS library quantification kit (Agilent Technologies). Multiplexed libraries were sequenced using a HiSeq platform (Illumina, San Diego, CA).

A panel covering 40 cancer-related genes, such as EGFR, BRAF, KRAS, PIK3CA, ALK, RET and ROS1, was used in this study. All genes, including oncogenes and tumor suppressor genes, were evaluating using full exon tiling arrays. For $A L K, R O S 1$ and RET, introns where rearrangements usually occur were also included.

\section{Variant calling}

Genomic alterations, such as point mutations, indels and gene rearrangements, were assessed in tissue samples, white blood cells and the plasma of all patients. Pre-alignment quality control was performed for each sample. Clean reads were obtained after removing adaptor 
sequences and low mapping quality reads. Reads aligned to reference genome hg19 were performed with BWA [43]. Duplication reads were marked and removed by picard. Variants in white blood cells were used to filter germline mutations. Somatic mutations were determined using the following filters: (i) the minimum average sequencing depth of the target for tissue samples was at least $200 \times$ and at least $1000 \times$ for plasma DNA; (ii) the minimum number of reads carrying the mutation was $>=5$; and (iii) variant allele frequency $>=0.2 \%$. Every somatic mutation identified in tDNA and ctDNA was checked by Integrative Genomics Viewer (IGV) software [44] and Samtools software. For point mutations and indels, variant frequencies less than $0.5 \%$ were further verified by the QuantStudio 3D digital PCR system (Life Technologies).

\section{Statistical analysis}

For statistical analysis, tissue DNA was considered a reference in considering concordance between tissue and plasma DNA. Matched tissue and plasma samples carrying the same gene mutations were considered true positives (TP). Matched tissue and plasma samples without somatic mutations were true negatives (TN). Gene mutations found in tissue samples, but not plasma samples, were classified as false negatives (FN), and gene mutations found in plasma samples, but not tissue samples, were false positives (FP). One sample with both false negative and positive mutation were counted as 0.5 in each category to maintain a total sample number of 39. Sensitivity, specificity and concordance were calculated according to TP, TN, FN and FP. The relationship between sample characteristics and gene mutations was measured by Fisher's exact or chi-square tests as appropriate. All statistical analyses were performed by R3.2.2.

\section{ACKNOWLEDGMENTS}

Sequencing was performed using the Illumina equipment at Novogene Co., Ltd in Beijing, China. We would like to thank the members of Novogene Bioinformatics Institute for their assistance in sample and data collection.

\section{CONFLICTS OF INTEREST}

Authors LL, YY, XW, ZYZ, JQZ, LGW, XHM and $\mathrm{ZJ}$ are employees of Novogene Bioinformatics Institute, Beijing, China. All other authors declare no competing financial interests.

\section{GRANT SUPPORT}

This research was supported by grants from the R\&D program of Novogene (RDYXHZ2016006) and the National Natural Science Foundation of China (81172233 to JC,), Specialized Research Fund for the Doctoral Program of Higher Education (20131202110004 to JC), Tianjin Science and Technology Support Program (12ZCDZSY16100 to JC).

\section{REFERENCES}

1. Chen W. Cancer statistics: updated cancer burden in China. Chin J Cancer Res. 2015; 27:1. doi: 10.3978/j.issn. 1000-9604.2015.02.07.

2. Eberhard DA, Johnson BE, Amler LC, Goddard AD, Heldens SL, Herbst RS, Ince WL, Janne PA, Januario T, Johnson DH, Klein P, Miller VA, Ostland MA, et al. Mutations in the epidermal growth factor receptor and in KRAS are predictive and prognostic indicators in patients with non-small-cell lung cancer treated with chemotherapy alone and in combination with erlotinib. J Clin Oncol. 2005; 23:5900-9. doi: 10.1200/JCO.2005.02.857.

3. Ludovini V, Bianconi F, Pistola L, Chiari R, Minotti V, Colella R, Giuffrida D, Tofanetti FR, Siggillino A, Flacco A, Baldelli E, Iacono D, Mameli MG, et al. Phosphoinositide3-kinase catalytic alpha and KRAS mutations are important predictors of resistance to therapy with epidermal growth factor receptor tyrosine kinase inhibitors in patients with advanced non-small cell lung cancer. J Thorac Oncol. 2011; 6:707-715. doi: 10.1097/JTO.0b013e31820a3a6b.

4. Tsao MS, Aviel-Ronen S, Ding K, Lau D, Liu N, Sakurada A, Whitehead M, Zhu CQ, Livingston R, Johnson DH, Rigas J, Seymour L, Winton T, et al. Prognostic and predictive importance of p53 and RAS for adjuvant chemotherapy in non small-cell lung cancer. J Clin Oncol. 2007; 25:5240-5247. doi: 10.1200/ JCO.2007.12.6953.

5. Diaz LA, Jr, Bardelli A. Liquid biopsies: genotyping circulating tumor DNA. J Clin Oncol. 2014; 32:579-586. doi: 10.1200/JCO.2012.45.2011.

6. Tan DS, Camilleri-Broet S, Tan EH, Alifano M, Lim WT, Bobbio A, Zhang S, Ng QS, Ang MK, Iyer NG, Takano A, Lim KH, Regnard JF, et al. Intertumor heterogeneity of non-small-cell lung carcinomas revealed by multiplexed mutation profiling and integrative genomics. Int J Cancer. 2014; 135:1092-1100. doi: 10.1002/ijc.28750.

7. Stroun M, Maurice P, Vasioukhin V, Lyautey J, Lederrey C, Lefort F, Rossier A, Chen XQ, Anker P. The origin and mechanism of circulating DNA. Ann N Y Acad Sci. 2000; 906:161-168.

8. Jahr S, Hentze H, Englisch S, Hardt D, Fackelmayer FO, Hesch RD, Knippers R. DNA fragments in the blood plasma of cancer patients: quantitations and evidence for their origin from apoptotic and necrotic cells. Cancer Res. 2001; 61:1659-1665.

9. Sozzi G, Conte D, Leon M, Ciricione R, Roz L, Ratcliffe C, Roz E, Cirenei N, Bellomi M, Pelosi G, Pierotti MA, Pastorino U. Quantification of free circulating DNA as 
a diagnostic marker in lung cancer. J Clin Oncol. 2003; 21:3902-3908. doi: 10.1200/JCO.2003.02.006.

10. Qiu M, Wang J, Xu Y, Ding X, Li M, Jiang F, Xu L, Yin R. Circulating tumor DNA is effective for the detection of EGFR mutation in non-small cell lung cancer: a metaanalysis. Cancer Epidemiol Biomarkers Prev. 2015; 24:206-212. doi: 10.1158/1055-9965.EPI-14-0895.

11. Lynch TJ, Bell DW, Sordella R, Gurubhagavatula S, Okimoto RA, Brannigan BW, Harris PL, Haserlat SM, Supko JG, Haluska FG, Louis DN, Christiani DC, Settleman J, et al. Activating mutations in the epidermal growth factor receptor underlying responsiveness of nonsmall-cell lung cancer to gefitinib. N Engl J Med. 2004; 350:2129-2139. doi: 10.1056/NEJMoa040938.

12. Rosell R, Moran T, Queralt C, Porta R, Cardenal F, Camps C, Majem M, Lopez-Vivanco G, Isla D, Provencio M, Insa A, Massuti B, Gonzalez-Larriba JL, et al. Screening for Epidermal Growth Factor Receptor Mutations in Lung Cancer. New England Journal of Medicine. 2009; 361:958-967. doi:10.1056/NEJMoa0904554.

13. Taniguchi K, Uchida J, Nishino K, Kumagai T, Okuyama T, Okami J, Higashiyama M, Kodama K, Imamura F, Kato K. Quantitative detection of EGFR mutations in circulating tumor DNA derived from lung adenocarcinomas. Clin Cancer Res. 2011; 17:7808-7815. doi: 10.1158/1078-0432.CCR-11-1712.

14. Kim HR, Lee SY, Hyun DS, Lee MK, Lee HK, Choi CM, Yang SH, Kim YC, Lee YC, Kim SY, Jang SH, Lee JC, Lee KY. Detection of EGFR mutations in circulating free DNA by PNA-mediated PCR clamping. J Exp Clin Cancer Res. 2013; 32:50. doi: 10.1186/1756-9966-32-50.

15. Shi Y, Au JS, Thongprasert S, Srinivasan S, Tsai CM, Khoa MT, Heeroma K, Itoh Y, Cornelio G, Yang PC. A prospective, molecular epidemiology study of EGFR mutations in Asian patients with advanced non-smallcell lung cancer of adenocarcinoma histology (PIONEER). J Thorac Oncol. 2014; 9:154-162. doi: 10.1097/ JTO.0000000000000033.

16. Qian X, Liu J, Sun Y, Wang M, Lei H, Luo G, Liu X, Xiong C, Liu D, Liu J, Tang Y. Circulating cell-free DNA has a high degree of specificity to detect exon 19 deletions and the single-point substitution mutation L858R in nonsmall cell lung cancer. Oncotarget. 2016; 7:29154-65. doi: 10.18632/oncotarget.8684.

17. Zhang H, Liu D, Li S, Zheng Y, Yang X, Li X, Zhang Q, Qin N, Lu J, Ren-Heidenreich L, Yang H, Wu Y, Zhang X, et al. Comparison of EGFR signaling pathway somatic DNA mutations derived from peripheral blood and corresponding tumor tissue of patients with advanced non-small-cell lung cancer using liquidchip technology. J Mol Diagn. 2013; 15:819-826. doi: 10.1016/j.jmoldx.2013.06.006.

18. Xu S, Lou F, Wu Y, Sun DQ, Zhang JB, Chen W, Ye H, Liu JH, Wei S, Zhao MY, Wu WJ, Su XX, Shi R, et al. Circulating tumor DNA identified by targeted sequencing in advanced-stage non-small cell lung cancer patients. Cancer Lett. 2016; 370:324-331. doi: 10.1016/j.canlet.2015.11.005.
19. Lebofsky R, Decraene C, Bernard V, Kamal M, Blin A, Leroy Q, Rio Frio T, Pierron G, Callens C, Bieche I, Saliou A, Madic J, Rouleau E, et al. Circulating tumor DNA as a non-invasive substitute to metastasis biopsy for tumor genotyping and personalized medicine in a prospective trial across all tumor types. Mol Oncol. 2015; 9:783-790. doi: 10.1016/j.molonc.2014.12.003.

20. Magdaleno SM, Cheng A, Petraroli R, Sheils O, Tops B, Corre DL, Kurth H, Blons H, Amato E, Mafficini A, Rachiglio AM, Reimann A, Noppen C, et al. Abstract 3575: The OncoNetwork Consortium: A global collaborative research study on the development and verification of an Ion AmpliSeq RNA gene lung fusion panel. Cancer Research. 2014; 74:3575. doi: 10.1158/1538-7445.am2014-3575.

21. Schwarzenbach H, Hoon DS, Pantel K. Cell-free nucleic acids as biomarkers in cancer patients. Nat Rev Cancer. 2011; 11:426-437. doi: 10.1038/nrc3066.

22. Diehl F, Schmidt K, Choti MA, Romans K, Goodman S, Li M, Thornton K, Agrawal N, Sokoll L, Szabo SA, Kinzler KW, Vogelstein B, Diaz LA, Jr. Circulating mutant DNA to assess tumor dynamics. Nat Med. 2008; 14 : 985-990. doi: 10.1038/nm.1789.

23. Kohler C, Barekati Z, Radpour R, Zhong XY. Cell-free DNA in the circulation as a potential cancer biomarker. Anticancer Res. 2011; 31:2623-2628.

24. Karlovich C, Goldman JW, Sun JM, Mann E, Sequist LV, Konopa K, Wen W, Angenendt P, Horn L, Spigel D, Soria JC, Solomon B, Camidge DR, et al. Assessment of EGFR Mutation Status in Matched Plasma and Tumor Tissue of NSCLC Patients from a Phase I Study of Rociletinib (CO-1686). Clin Cancer Res. 2016; 22: 2386-2395. doi: 10.1158/1078-0432.CCR-15-1260.

25. Han JY, Choi JJ, Kim JY, Han YL, Lee GK. PNA clampingassisted fluorescence melting curve analysis for detecting EGFR, KRAS mutations in the circulating tumor DNA of patients with advanced non-small cell lung cancer. BMC Cancer. 2016; 16:627. doi: 10.1186/s12885-016-2678-2.

26. Chai X, Ren P, Wei B, Ma J, Mai L, Cram DS, Song Y, Guo Y. A comparative study of EGFR oncogenic mutations in matching tissue and plasma samples from patients with advanced non-small cell lung carcinoma. Clin Chim Acta. 2016; 457:106-111. doi: 10.1016/j.cca.2016.04.003.

27. Sacher AG, Paweletz C, Dahlberg SE, Alden RS, O'Connell A, Feeney N, Mach SL, Janne PA, Oxnard GR. Prospective Validation of Rapid Plasma Genotyping for the Detection of EGFR, KRAS Mutations in Advanced Lung Cancer. JAMA Oncol. 2016; 2:1014-1022. doi: 10.1001/ jamaoncol.2016.0173.

28. Sholl LM, Xiao Y, Joshi V, Yeap BY, Cioffredi LA, Jackman DM, Lee C, Janne PA, Lindeman NI. EGFR mutation is a better predictor of response to tyrosine kinase inhibitors in non-small cell lung carcinoma than FISH, CISH, and immunohistochemistry. Am J Clin Pathol. 2010; 133:922-934. doi: 10.1309/AJCPST1CTHZS3PSZ. 
29. Lee JY, Qing X, Xiumin W, Yali B, Chi S, Bak SH, Lee HY, Sun JM, Lee SH, Ahn JS, Cho EK, Kim DW, Kim HR, et al. Longitudinal monitoring of EGFR mutations in plasma predicts outcomes of NSCLC patients treated with EGFR TKIs: Korean Lung Cancer Consortium (KLCC12-02). Oncotarget. 2016; 7:6984-6993. doi: 10.18632/ oncotarget. 6874 .

30. An SJ, Chen ZH, Su J, Zhang XC, Zhong WZ, Yang JJ, Zhou Q, Yang XN, Huang L, Guan JL, Nie Q, Yan HH, Mok TS, et al. Identification of enriched driver gene alterations in subgroups of non-small cell lung cancer patients based on histology and smoking status. PLoS One. 2012; 7:e40109. doi: 10.1371/journal.pone.0040109.

31. Bai H, Mao L, Wang HS, Zhao J, Yang L, An TT, Wang X, Duan CJ, Wu NM, Guo ZQ, Liu YX, Liu HN, Wang YY, et al. Epidermal growth factor receptor mutations in plasma DNA samples predict tumor response in Chinese patients with stages IIIB to IV non-small-cell lung cancer. J Clin Oncol. 2009; 27:2653-2659. doi: 10.1200/ JCO.2008.17.3930.

32. Wu YL, Zhou Q. Clinical trials and biomarker research on lung cancer in China. Expert Opin Ther Targets. 2012; 16:S45-50. doi: 10.1517/14728222.2011.630663.

33. Mok TS, Wu YL, Thongprasert S, Yang CH, Chu DT, Saijo N, Sunpaweravong P, Han B, Margono B, Ichinose Y, Nishiwaki Y, Ohe Y, Yang JJ, et al. Gefitinib or carboplatinpaclitaxel in pulmonary adenocarcinoma. N Engl J Med. 2009; 361:947-957. doi: 10.1056/NEJMoa0810699.

34. Rosell R, Carcereny E, Gervais R, Vergnenegre A, Massuti B, Felip E, Palmero R, Garcia-Gomez R, Pallares C, Sanchez JM, Porta R, Cobo M, Garrido P, et al. Erlotinib versus standard chemotherapy as first-line treatment for European patients with advanced EGFR mutation-positive non-small-cell lung cancer (EURTAC): a multicentre, open-label, randomised phase 3 trial. Lancet Oncol. 2012; 13:239-246. doi: 10.1016/ S1470-2045(11)70393-X.

35. Kobayashi S, Boggon TJ, Dayaram T, Janne PA, Kocher O, Meyerson M, Johnson BE, Eck MJ, Tenen DG, Halmos B. EGFR mutation and resistance of non-small-cell lung cancer to gefitinib. N Engl J Med. 2005; 352:786-792. doi: 10.1056/NEJMoa044238.

36. Del Re M, Tiseo M, Bordi P, D'Incecco A, Camerini A, Petrini I, Lucchesi M, Inno A, Spada D, Vasile E, Citi V, Malpeli G, Testa E, et al. Contribution of KRAS mutations and c.2369C > T (p.T790M) EGFR to acquired resistance to EGFR-TKIs in EGFR mutant NSCLC: a study on circulating tumor DNA. Oncotarget. 2016 Jan 20. doi: 10.18632/oncotarget.6957. [Epub ahead of print].

37. Pillai RN, Ramalingam SS. The biology and clinical features of non-small cell lung cancers with EML4-ALK translocation. Curr Oncol Rep. 2012; 14:105-110. doi: 10.1007/s11912-012-0213-4.

38. Katayama R, Friboulet L, Koike S, Lockerman EL, Khan TM, Gainor JF, Iafrate AJ, Takeuchi K, Taiji M, Okuno Y, Fujita N, Engelman JA, Shaw AT. Two novel ALK mutations mediate acquired resistance to the nextgeneration ALK inhibitor alectinib. Clin Cancer Res. 2014; 20:5686-96. doi: 10.1158/1078-0432.CCR-14-1511.

39. Kwak EL, Bang YJ, Camidge DR, Shaw AT, Solomon B, Maki RG, Ou SH, Dezube BJ, Janne PA, Costa DB, Varella-Garcia M, Kim WH, Lynch TJ, et al. Anaplastic lymphoma kinase inhibition in non-small-cell lung cancer. N Engl J Med. 2010; 363:1693-1703. doi: 10.1056/ NEJMoa1006448.

40. Inamura K, Takeuchi K, Togashi Y, Hatano S, Ninomiya H, Motoi N, Mun MY, Sakao Y, Okumura S, Nakagawa K, Soda M, Choi YL, Mano H, et al. EML4-ALK lung cancers are characterized by rare other mutations, a TTF-1 cell lineage, an acinar histology, and young onset. Mod Pathol. 2009; 22:508-515. doi: 10.1038/modpathol.2009.2.

41. Shaw AT, Yeap BY, Mino-Kenudson M, Digumarthy SR, Costa DB, Heist RS, Solomon B, Stubbs H, Admane S, McDermott U, Settleman J, Kobayashi S, Mark EJ, et al. Clinical features and outcome of patients with non-smallcell lung cancer who harbor EML4-ALK. J Clin Oncol. 2009; 27:4247-4253. doi: 10.1200/JCO.2009.22.6993.

42. Liang W, He Q, Chen Y, Chuai S, Yin W, Wang W, Peng G, Zhou C, He J. Metastatic EML4-ALK fusion detected by circulating DNA genotyping in an EGFR-mutated NSCLC patient and successful management by adding ALK inhibitors: a case report. BMC Cancer. 2015; 16:62. doi: 10.1186/s12885-016-2088-5.

43. Li H, Durbin R. Fast and accurate long-read alignment with Burrows-Wheeler transform. Bioinformatics. 2010; 26:589-595. doi: 10.1093/bioinformatics/btp698.

44. Robinson JT, Thorvaldsdottir H, Winckler W, Guttman M, Lander ES, Getz G, Mesirov JP. Integrative genomics viewer. Nat Biotechnol. 2011; 29:24-26. doi: 10.1038/ nbt.1754. 